\title{
Early vascular unclamping reduces warm ischaemia time in \\ robot-assisted laparoscopic partial nephrectomy [version 1;
}

\section{peer review: 2 approved]}

\author{
Kevin Lah ${ }^{1,2}$, Devang Desai ${ }^{1,2}$, Charles Chabert ${ }^{3}$, Christian Gericke ${ }^{2,4}$, \\ Troy Gianduzzo ${ }^{1-3}$
}

\author{
${ }^{1}$ Royal Brisbane and Women's Hospital, Brisbane, Queensland, 4006, Australia \\ ${ }^{2}$ University of Queensland School of Medicine, Brisbane, Queensland, 4006, Australia \\ ${ }^{3}$ The Wesley Hospital, Brisbane, Queensland, 4066, Australia \\ ${ }^{4}$ The Wesley Research Institute, Brisbane, Queensland, 4066, Australia
}

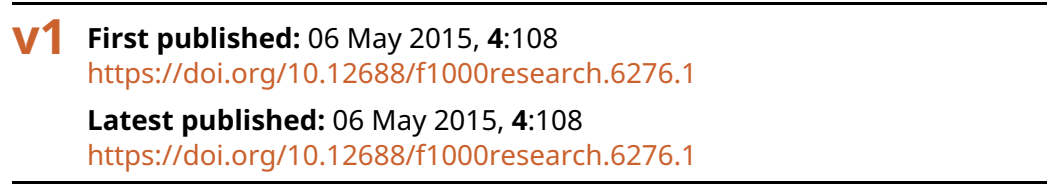

\section{Abstract}

Introduction: The aim of this study was to assess the outcomes of early vascular release in robot-assisted laparoscopic partial nephrectomy (RAPN) to reduce warm ischaemia time (WIT) and minimise renal dysfunction. RAPN is increasingly utilised in the management of small renal masses. To this end it is imperative that WIT is kept to a minimum to maintain renal function.

Methods: RAPN was performed via a four-arm robotic transperitoneal approach. The renal artery and vein were individually clamped with robotic vascular bulldog clamps to allow cold scissor excision of the tumour. The cut surface was then sutured with one or two running 3-0 V-Loc ${ }^{\mathrm{TM}}$ sutures, following which the vascular clamps were released. Specific bleeding vessels were then selectively oversewn and the collecting system repaired. Renorrhaphy was then completed using a running horizontal mattress 0-0 V-Loc ${ }^{\mathrm{TM}}$ suture.

Results: A total of 16 patients underwent RAPN with a median WIT of 15 minutes (range: 8-25), operative time 230 minutes (range: 180-280) and blood loss of $100 \mathrm{~mL}$ (range: 50-1000). There were no transfusions, secondary haemorrhages or urine leaks. There was one focal positive margin in a central $5.5 \mathrm{~cm}$ pT3a renal cell carcinomas (RCC). Long-term estimated glomerular filtration rate (eGFR) was not significantly different to pre-operative values.

Conclusion: In this patient series, early vascular release effectively minimised WIT and maintained renal function without compromising perioperative safety.

Keywords

Robot-assisted laparoscopy, Partial nephrectomy, Renal function, Renal Mass

\section{Open Peer Review \\ Approval Status \\ 1 2 \\ version 1 \\ 06 May 2015

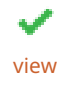 \\ view \\ 1. Prem Rashid ID, The University of New \\ South Wales, Sydney, Australia \\ 2. Mark William Louie-Johnsun, Wyong \\ Hospital, Sydney, Australia \\ Any reports and responses or comments on the article can be found at the end of the article.}


Corresponding author: Troy Gianduzzo (troygianduzzo@gmail.com)

Competing interests: No competing interests were disclosed.

Grant information: The author(s) declared that no grants were involved in supporting this work.

Copyright: ( 2015 Lah K et al. This is an open access article distributed under the terms of the Creative Commons Attribution License, which permits unrestricted use, distribution, and reproduction in any medium, provided the original work is properly cited. Data associated with the article are available under the terms of the Creative Commons Zero "No rights reserved" data waiver (CC0 1.0 Public domain dedication).

How to cite this article: Lah $K$, Desai $D$, Chabert $C$ et al. Early vascular unclamping reduces warm ischaemia time in robot-assisted laparoscopic partial nephrectomy [version 1; peer review: 2 approved] F1000Research 2015, 4:108

https://doi.org/10.12688/f1000research.6276.1

First published: 06 May 2015, 4:108 https://doi.org/10.12688/f1000research.6276.1 


\section{Introduction}

The incidence of diagnoses of renal masses is on the rise with increased use of abdominal imaging ${ }^{1}$. Nephron-sparing surgery (NSS), such as robotic-assisted laparoscopic partial nephrectomy (RAPN) is increasingly recommended to preserve long-term renal function $^{2,3}$. This is particularly important given the increasing prevalence of diabetes mellitus and hypertension in the community ${ }^{4,5}$. The American Urological Association recommends NSS as the treatment of choice for most T1 renal masses ${ }^{6}$. NSS has been shown to reduce the long-term risks of renal dysfunction, and cardiovascular morbidity, as well as overall mortality when compared to radical nephrectomy ${ }^{7,8}$. The duration of warm ischaemia time (WIT) during partial nephrectomy (PN) is critically important in achieving these outcomes. Thompson and colleagues ${ }^{9}$ found that a WIT of 25 minutes or longer was significantly associated with new onset of stage IV chronic kidney disease and concluded that "every minute of ischaemia counts" in the preservation of renal function ${ }^{10}$. Ongoing refinement of the technique over the last decade to minimise ischaemia time has been the challenge in mastering PN.

Laparoscopic PN (LPN) is a not a procedure for any novice laparoscopic urologist ${ }^{11}$. The difficulties in tumour excision and reconstruction of the collecting system and renal cortex can be improved by the use of robot-assisted laparoscopic instruments. This allows a greater degree of motion and dexterity which may allow the surgeon to reduce WIT. Other techniques to decrease WIT have included the use of intra-arterial hypothermic perfusion ${ }^{12}$, intra-corporeal placement of ice slush ${ }^{13}$ and specific refinements in clamping renal artery and vein, including the early vascular release technique ${ }^{14}$. This study presents the initial experience of early vascular release as a means to minimise WIT during RAPN.

\section{Methods}

With UnitingCare Health Ethics Committee approval, nr. 2013.25.96, the outcomes of RAPN of two oncology fellowshiptrained surgeons (TG and CC) were analysed. Data from 16 consecutive patients was prospectively collected between July 2011 and September 2013.

Pre-operative data included: age, gender, body mass index, American Society of Anesthesiologists Physical status classification (ASA), side of the mass, pre-operative renal function (estimated glomerular filtration rate), tumour size on imaging and relevant medical history (i.e. previous abdominal surgery). Intraoperative data included: operative duration, console time, WIT, estimated blood loss and intraoperative complications. Operative duration was defined as skin-to-skin time, and console time defined as the time during which the robotic interface was used during the procedure. Perioperative data included: complications, day 1 post-operative renal function and length of hospital stay. Post-operative data included renal function at 6 months, and tumour histology, stage, margin and size. Pathological analysis was performed by a single uropathologist experienced in partial nephrectomy assessment.

RAPN was performed via a four-arm transperitoneal approach in a modified lateral position with a $30^{\circ}$ tilt and the table at $20-30^{\circ}$ contralateral tilt. An ipsilateral ureteric catheter is routinely used to allow retrograde instillation of methylene blue to check collecting system integrity. The kidney was mobilized in the standard fashion whereby the colon was reflected medially, the ureter elevated with the fourth arm and the duodenum kocherised for right-sided tumours. The renal vessels were then isolated and looped with vessel loops. Gerota's fascia was then incised and the kidney defatted in order to localise the mass. Care was taken to leave perinephric fat directly on the mass. The renal mass was then assessed with intraoperative ultrasound to ascertain its depth and to plan the margin of incision. Both renal artery and vein were clamped using robotic bulldog clamps and the tumour excised with cold scissor dissection. Renorrhaphy was performed using one or two 2-0 V-Loc ${ }^{\mathrm{TM}}$ absorbable polyglyconate knotless sutures (Covidien Inc.), following which the bulldog clamps were released. This early release allowed specific bleeding vessels to be immediately positively identified and specifically suture ligated with figure-of-8, 3-0 vicryl sutures. Collecting system defects were specifically repaired and the integrity assessed with retrograde instillation of methylene blue. Cortical reconstruction was performed using a single, running horizontal mattress 12 inch 0-0 V-Loc ${ }^{\mathrm{TM}}$ suture. Floseal ${ }^{\circledR}$ (Baxter Corp.) was applied to the closed defect.

\section{Statistical data analysis}

Numerical data was summarised using median and range (Microsoft Excel), and analysed using the Wilcoxon signed-rank test (www. socscistatistics.com) where appropriate. A P $<0.05$ was considered to indicate statistical significance. Demographics and categorical data were summarised in table format.

\section{Results}

A total of 16 patients underwent RAPN. There were ten males and six females with a median age of 66.5 (range 48 to 80 years). There were nine left sided lesions and seven right sided lesions. The majority of the masses were exophytic with a median size of $2.65 \mathrm{~cm}$. Table 1 shows the demographics.

Perioperative data are recorded in Table 2. Day 1 eGFR was marginally reduced compared to pre-operative levels $(\mathrm{p}<0.01)$. However this was not clinically significant and by 6 months eGFR had returned to baseline $(\mathrm{p}=0.11)$. The median operative time was 230 minutes with 192.5 minutes of console time. Median WIT was 15 minutes and median blood loss was $100 \mathrm{~mL}$. The median hospital length of stay was 2 days. There were no transfusions, urine leaks, or post-operative haemorrhage. Histopathology demonstrated nine

Table 1. Demographics.

\begin{tabular}{|l|c|}
\hline N & 16 \\
\hline Gender (M:F) & $10: 6$ \\
\hline Age Median (Range) & 66.5 years $(48-80)$ \\
\hline ASA & 2 \\
\hline BMI Median (Range) & $27.1(20.1-35.3)$ \\
\hline Tumour side (L:R) & $9: 7$ \\
\hline Exophytic : Endophytic tumour & $13: 3$ \\
\hline
\end{tabular}

ASA: American Society of Anesthesiologists Physical status classification 
clear cell renal cell carcinomas (RCC), three papillary RCC, three angiomyolipoma and three eosinophilic variant clear cell RCC (Table 3). Tumour abutted the resection margin in one case of a central $5.5 \mathrm{~cm}$ mass which demonstrated renal sinus and vascular invasion on frozen section. A completion nephrectomy was then immediately performed given these high-risk features and also given that the contra-lateral kidney and pre-operative renal function were normal. There was no residual tumour in the remaining kidney. One patient had a grade 1 Clavien-Dindo classification who had self-resolved neuralgic pain. No cases were converted to an open operation. Our study is compared with international data in Table 4.

\section{Dataset 1. Raw data}

http://dx.doi.org/10.5256/f1000research.6276.d46769

Pre-, post- and perioperative data for patients undergoing robotassisted laparoscopic partial nephrectomy ${ }^{23}$.

\begin{tabular}{l}
\hline Table 2. Perioperative data. \\
\begin{tabular}{|l|l|}
\hline Pre-op eGFR Median (Range) & $74 \mathrm{ml} / \mathrm{min} / 1.73 \mathrm{~m}^{2}(53-90)$ \\
\hline Day 1 Post-op eGFR Median (Range) & $63 \mathrm{ml} / \mathrm{min} / 1.73 \mathrm{~m}^{2}(39-90)[\mathrm{p}<0.01]$ \\
\hline 6 Month eGFR Median (Range) & $70 \mathrm{~mL} / \mathrm{min} / 1.73 \mathrm{~m}^{2}(53-90)[\mathrm{p}=0.11]$ \\
\hline Operative time (Range) & $230 \mathrm{mins}(180-280)$ \\
\hline Console time (Range) & $192.5 \mathrm{mins}(150-230)$ \\
\hline WIT (Range) & $15 \mathrm{mins}(8-25)$ \\
\hline Blood loss Median (Range) & $100 \mathrm{ml}(50-1000)$ \\
\hline Length of stay & 2 days (1-6) \\
\hline Complications & Neuralgic pain self resolved \\
\hline
\end{tabular}
\end{tabular}

eGFR: estimated glomerular filtration rate. [p value] compared with pre-op.

\begin{tabular}{|l|c|}
\hline Table 3. Histopathology. \\
\hline Clear Cell RCC & 9 \\
\hline Papillary RCC & 3 \\
\hline AML & 1 \\
\hline Eosinophilic variant clear cell RCC & 3 \\
\hline Positive Margins & 1 \\
\hline
\end{tabular}

RCC: Renal cell carcinoma; AML: Angiomyolipoma

Table 4. Study comparison.

\begin{tabular}{|l|l|l|}
\hline Median (Range) & Current Study $(n=16)$ & San Francisco et al. $(n=12)$ \\
\hline Operative time & 230 mins (180-280) & 227 mins (176-315) \\
\hline WIT & 15 mins (8-25) & 16 mins (11-25) \\
\hline Blood loss & $100 \mathrm{~mL}(50-1000)$ & $150 \mathrm{~mL}(50-500)$ \\
\hline Length of stay & 2 days (2-6) & 2 days (2-7) \\
\hline Positive margins & $1(6.25 \%)$ & $1(8 \%)$ \\
\hline
\end{tabular}

WIT: Warm ischaemia time 


\section{Discussion}

RAPN is an effective surgical alternative in NSS in which the ultimate goal is to achieve the "trifecta" of a negative cancer margin, minimal decrease in renal function and an absence of complications ${ }^{14}$. The use of robotic technology can assist in achieving these outcomes and in particular, minimise renal dysfunction by reducing WIT. Laparoscopic partial nephrectomy not only has a steep learning curve to achieve acceptable WIT but also requires skills that are challenged by its technical difficulties, including the use of instruments that have limited degrees-of-freedom. The robot application in PN allows a three-dimensional vision with magnification and instrument arms that are versatile with its EndoWrist ${ }^{\circledR}$ technology, providing increased angle and maneuverability for tumour excision and repair of the renal defect $^{15}$.

Various methods have been employed in the past to lessen the ischaemic injury. Intra-arterial hypothermic perfusion was used in early series of $\mathrm{LPN}^{12}$ as was intra-corporeal placement of ice slush $^{13}$. However endovascular hypothermia came with the added risks of placing an arterial catheter and administration of extra fluid for patients with poor cardiopulmonary performance status. Intracorporeal cooling reduced the working space and exposure of the hilum.

There has been an ongoing refinement of clamping techniques to reduce WIT, progressing from conventional clamping of both renal artery and vein ${ }^{10}$ to early unclamping ${ }^{14,16,17}$. With the introduction of early unclamping, where the clamp is released once a central medullary running suture is placed and the rest of the kidney repaired with the revascularised perfused kidney, Nguyen and Gill ${ }^{16}$ were able to decrease WIT in LPN from 31.3 minutes to 13.9 minutes. The overall complications including estimated blood loss were not significantly different compared with the standard clamping technique. Furthermore, surgeons have pushed the boundaries of minimal ischaemia by selectively micro-clamping arteries supplying the tumour ${ }^{18,19}$ and in one study, without clamping and aiming for "zero ischaemia" 20 . This clamp-less group of eight patients had significantly reduced operative time but an increased blood loss. The transfusion and renal dysfunction were similar to the clamped group.

The technique of early vascular release has been translated from LPN to RAPN ${ }^{17}$. San Francisco et al. described 12 patients who underwent RAPN with early vascular release (Table 4$)^{17}$. In that series, the median WIT was 16 minutes, median operative time 227 minutes, median estimated blood loss $150 \mathrm{~mL}$ and length of stay 2 days. These results are comparable to the present study (Table 4).

Kaouk and colleagues ${ }^{21}$ reported their single-institution's 252 RAPNs with early unclamping technique when deemed appropriate. Their study confirmed that the longer the duration of WIT, the greater the decrease in renal dysfunction at 1 month. Kucharczyk and colleagues reported an Australian series of 50 consecutive patients undergoing RAPN by a single surgeon ${ }^{22}$. The mean WIT was 17.8 minutes, operative time was 151 minutes and estimated blood loss was $171.1 \mathrm{ml}$. They achieved no positive malignant surgical margins and a clinically stable renal function post-operatively.

In this series, the outcomes of early vascular release were comparable to the literature with short WIT and no morbidity from intraoperative or postoperative haemorrhage or urine leak. The limitations of this study include a small sample size, and the lack of a randomised comparison to other techniques.

In conclusion, early vascular release following tumour excision during RAPN resulted in short WIT with minimal morbidity and preserved renal function.

\section{Data availability}

F1000Research: Dataset 1. Raw data, 10.5256/f1000research.6276. $\mathrm{d} 46769^{23}$

\section{Consent}

All patients gave consent for collection of data for research purposes.

\section{Author contributions}

$\mathrm{KL}$ and DD prepared the first draft of the manuscript and analysed the collected data from TG and CC. TG, CC and CG contributed to the design and preparation of the manuscript. All authors were involved in the revision of the draft manuscript and have agreed to the final content.

\section{Competing interests}

No competing interests were disclosed.

\section{Grant information}

The author(s) declared that no grants were involved in supporting this work.
1. Gill IS, Aron M, Gervais DA, et al.: Clinical practice. Small renal mass. N Eng J Med. 2010; 362(7): 624-34.

PubMed Abstract | Publisher Full Text

2. Ljungberg B, Cowan NC, Hanbury DC, et al.: EAU guidelines on renal cell carcinoma: the 2010 update. Eur Urol. 2010; 58(3): 398-406. PubMed Abstract | Publisher Full Text

3. Uzzo RG, Novick AC: Nephron sparing surgery for renal tumors: indications, techniques and outcomes. J Urol. 2001; 166(1): 6-18. PubMed Abstract | Publisher Full Text

4. World Health Organization. World Health Statistics 2012. Reference Source
5. Wild S, Roglic G, Green A, et al:: Global prevalence of diabetes: estimates for the year $\mathbf{2 0 0 0}$ and projections for 2030. Diab Care. 2004; 27(5): 1047-1053.

PubMed Abstract | Publisher Full Text

6. Novick AC, Campbell SC, Belldegrun A, et al:: Guideline for management of the clinical stage 1 renal mass. Am Urological Assoc. 2009. Reference Source

7. Miyamoto K, Inoue S, Kajiwara M, et al.: Comparison of renal function after partial nephrectomy and radical nephrectomy for renal cell carcinoma. Urol Int. 2012; 89(2): 227-232. PubMed Abstract | Publisher Full Text 
8. Weight CJ, Larson BT, Fergany AF, et al.: Nephrectomy induced chronic rena insufficiency is associated with increased risk of cardiovascular death and death from any cause in patients with localized $\mathbf{c T 1 b}$ renal masses. $J$ Urol. 2010; 183(4): 1317-1323.

PubMed Abstract | Publisher Full Text

9. Thompson RH, Lane BR, Lohse CM, et al.: Renal function after partial nephrectomy: effect of warm ischemia relative to quantity and quality of preserved kidney. Urology. 2012; 79(2): 356-360.

PubMed Abstract | Publisher Full Text

10. Thompson RH, Lane BR, Lohse CM, et al.: Every minute counts when the renal hilum is clamped during partial nephrectomy. Eur Urol. 2010; 58(3): 340-345. PubMed Abstract | Publisher Full Text

11. Rashid P, Goad J, Aron M, et al:: Laparoscopic partial nephrectomy: integration of an advanced laparoscopic technique. ANZ J Surg. 2008; 78(6): 471-475. PubMed Abstract | Publisher Full Text

12. Janetschek G, Abdelmaksoud A, Bagheri F, et al:: Laparoscopic partial nephrectomy in cold ischemia: renal artery perfusion. J Urol. 2004; 171(1): 68-71. PubMed Abstract | Publisher Full Text

13. Gill IS, Abreu SC, Desai MM, et al.: Laparoscopic ice slush renal hypothermia for partial nephrectomy: the initial experience. J Urol. 2003; 170(1): 52-56. PubMed Abstract | Publisher Full Text

14. Hung AJ, Cai J, Simmons MN, et al.: "Trifecta" in partial nephrectomy. J Urol. 2013; 189(1): 36-42.

PubMed Abstract | Publisher Full Text

15. Ficarra V, Novara G, Volpe A, et al:: Robot-assisted vs traditional laparoscopic partial nephrectomy: the time for meta-analysis has not yet arrived. BJU Int 2013; 112(4): E334-E336.

PubMed Abstract | Publisher Full Text
16. Nguyen MM, Gill IS: Halving ischemia time during laparoscopic partial nephrectomy. J Urol. 2008; 179(2): 627-632; discussion 632. PubMed Abstract | Publisher Full Text

17. San Francisco IF, Sweeney MC, Wagner AA, et al.: Robot-assisted partial nephrectomy: early unclamping technique. J Endourol. 2011; 25(2) 305-308.

PubMed Abstract | Publisher Full Text

18. Gill IS, Eisenberg MS, Aron M, et al.: "Zero ischemia" partial nephrectomy: novel laparoscopic and robotic technique. Eur Urol. 2011; 59(1): 128-134. PubMed Abstract | Publisher Full Text

19. Abreu ALC, Gill IS, Desai MM: Zero-ischaemia robotic partial nephrectomy (RPN) for hilar tumours. BJU Int. 2011; 108(6 Pt 2): 948-954.

PubMed Abstract | Publisher Full Text

20. White WM, Goel RK, Haber G, et al:: Robotic partial nephrectomy without renal hilar occlusion. BJU Int. 2010; 105(11): 1580-1584. PubMed Abstract | Publisher Full Text

21. Kaouk JH, Hillyer SP, Autorino R, et al.: $\mathbf{2 5 2}$ Robotic partial nephrectomies: Evolving renorrhaphy technique and surgical outcomes at a single institution. Urology. 2011; 78(6): 1338-1344. PubMed Abstract | Publisher Full Text

22. Kucharczyk JR, Basto M, Landau A, et al.: Early experience and operative technique of robotic-assisted partial nephrectomy. ANZ J Surg. 2014 PubMed Abstract | Publisher Full Text

23. Lah K, Desai D, Chabert C, et al:: Dataset 1 in: Early vascular unclamping reduces warm ischaemia time in robot-assisted laparoscopic partial nephrectomy. F1000Research. 2015.

Data Source 


\section{Open Peer Review}

\section{Current Peer Review Status:}

\section{Version 1}

Reviewer Report 13 May 2015

https://doi.org/10.5256/f1000research.6732.r8577

(C) 2015 Louie-Johnsun M. This is an open access peer review report distributed under the terms of the Creative Commons Attribution License, which permits unrestricted use, distribution, and reproduction in any medium, provided the original work is properly cited.

\section{Mark William Louie-Johnsun}

Department of Urology, Wyong Hospital, Sydney, NSW, Australia

This article highlights the early solid results of two oncology fellowship-trained surgeons performing robot assisted laparoscopic partial nephrectomy. The short WIT with minimal perioperative complications highlights this complex operation can be performed expertly in well trained surgeons even in their early experience.

Competing Interests: No competing interests were disclosed.

I confirm that I have read this submission and believe that I have an appropriate level of expertise to confirm that it is of an acceptable scientific standard.

Reviewer Report 12 May 2015

https://doi.org/10.5256/f1000research.6732.r8579

(C) 2015 Rashid P. This is an open access peer review report distributed under the terms of the Creative Commons Attribution License, which permits unrestricted use, distribution, and reproduction in any medium, provided the original work is properly cited.

\section{Prem Rashid}

Department of Urology, Port Macquarie Base Hospital, Rural Clinical School, The University of New South Wales, Sydney, NSW, Australia

This paper on the early experience of robotic LPN highlights the complexity of the procedure and the possible outcomes with good background preparation. The results are helpful to guide those embarking on LPN or robotic assisted LPN. It is well written. The methodology and conclusions are sound. 
Competing Interests: No competing interests were disclosed.

I confirm that I have read this submission and believe that I have an appropriate level of expertise to confirm that it is of an acceptable scientific standard.

The benefits of publishing with F1000Research:

- Your article is published within days, with no editorial bias

- You can publish traditional articles, null/negative results, case reports, data notes and more

- The peer review process is transparent and collaborative

- Your article is indexed in PubMed after passing peer review

- Dedicated customer support at every stage

For pre-submission enquiries, contact research@f1000.com 